\title{
The Role of the Insular Cortex in Naloxone-Induced Conditioned Place Aversion in Morphine-Dependent Mice
}

\author{
Fang WANG ${ }^{1^{*}}$, Xiaolong JING ${ }^{1 *}$, Jingyu YANG ${ }^{1}$, Huan WANG ${ }^{1}$, Rongwu XIANG ${ }^{2}$, \\ Wenyan HAN ${ }^{1}$, Xinxin LIU ${ }^{1}$, Chunfu WU ${ }^{1}$ \\ ${ }^{*}$ These authors contributed equally to this work. \\ ${ }^{1}$ Department of Pharmacology, Shenyang Pharmaceutical University, Shenyang, China, \\ ${ }^{2}$ Mathematics Teaching and Research Section, Shenyang Pharmaceutical University, Shenyang, \\ China
}

Received June 16, 2015

Accepted November 12, 2015

On-line March 15, 2016

\begin{abstract}
Summary
A negative emotional state resulting from the withdrawal of drug addiction is thought to be an important factor that triggers and exacerbates relapse. Since the insular cortex is a key brain structure involved in the modulation of negative emotions, we investigated whether the integrity of the insular cortex was important for motivational aversion associated with morphine withdrawal as well as whether this kind of negative emotion induced neuroadaptation in the insular cortex. In this present study, a sensitive mouse conditioned place aversion (CPA) model measuring the motivational aversion of morphine withdrawal was first established. Our results showed that bilateral insular cortex lesions by kainic acid completely inhibited the expression of CPA. The expression of $\mathrm{Fos} B / \Delta \mathrm{FosB}$ in the insular cortex was significantly increased $24 \mathrm{~h}$ after the CPA regime was performed, but the expression of c-Fos in the insular cortex did not changed. These findings indicate that the integrity of the insular cortex is essential to motivational aversion associated with morphine withdrawal, and that this kind of aversion induces neuroadaptation, observed as the increase of $F o s B / \Delta F o s B$ expression, in the insular cortex.
\end{abstract}

\section{Key words}

Insular cortex - Morphine - Naloxone - Conditioned place aversion • FosB/ $\Delta$ FosB

\section{Corresponding author}

C.F. Wu, Department of Pharmacology, Shenyang Pharmaceutical
University, Shenyang, 110016, China.

E-mail: chunfuw@gmail.com or wucf@syphu.edu.cn

\section{Introduction}

It is well known that drug addiction is a chronically relapsing mental disorder that progresses from impulsivity to compulsivity in a collapsed cycle of addiction comprised of three stages: preoccupation/anticipation, binge intoxication, and withdrawal/negative affect (Edwards and Koob 2010, Koob 2009, Koob and Volkow 2010). A negative emotional state resulting from withdrawal is thought to contribute to the exacerbation of the relapse (Edwards and Koob 2010, Koob 2009, Koob and Volkow 2010). Until now, most neuroanatomical data and functional observations revealed that the negative emotional state of withdrawal engage the activation of the extended amygdala, a neuroanatomical substrate involved in the modulation of negative emotions. In addition to the extended amygdala, the insular cortex is also well known as a key brain structure involved in the modulation of negative emotions, especially the aversive emotion (Slouzkey et al. 2013, Stark et al. 2007). However, it is recently that the influence of the insular cortex on the field of addiction gradually gained more attention. Evidence showed that dysfunction of the insular cortex led to a profound disruption of addiction to cigarette smoking in human (Naqvi et al. 2007) and amphetamine-induced 
conditioned place preference in rats (Contreras et al. 2007). Subsequently, accumulating evidence supported the important role of the rat's insular cortex in the processes of nicotine-seeking (Abdolahi et al. 2010, Forget et al. 2010), cocaine addiction (Di Pietro et al. 2008), and opiate affective learning (Li et al. 2013). However, little is known about the role of the insular cortex on the motivational aversion associated with withdrawal in mice as well as its possible underlying mechanism.

The Fos family transcription factors act as initiators and markers of neuronal activation in response to addiction drugs (Marttila et al. 2006, Nestler et al. 2001). c-Fos is a marker for postsynaptic activation after exposure to drugs (McClung et al. 2004, Morgan and Curran 1991, Nestler et al. 2001). $\Delta$ FosB is thought to be a type of molecular switch that gradually converts acute responses into relatively stable adaptations that contribute to the long-term neural and behavioral plasticity that underlies chronic drug exposure (McClung et al. 2004, Nestler et al. 2001). It is unknown however, whether the expressions of Fos family transcription factors in the insular cortex might be changed after the expression of the CPA model.

In the present study, we first established a conditioned place aversion (CPA) model, which was induced by naloxone withdrawal in morphine-dependent mice to measure conditioned aversion. Kainic acid was used to lesion the insular cortex bilaterally to investigate the influence of the integrity of the insular cortex on the motivational aversion associated with withdrawal. The expressions of FosB/ $\Delta$ FosB and c-Fos in the insular cortex were also evaluated to explore whether this kind of aversion induced any change in expression of the Fos family of transcription factors.

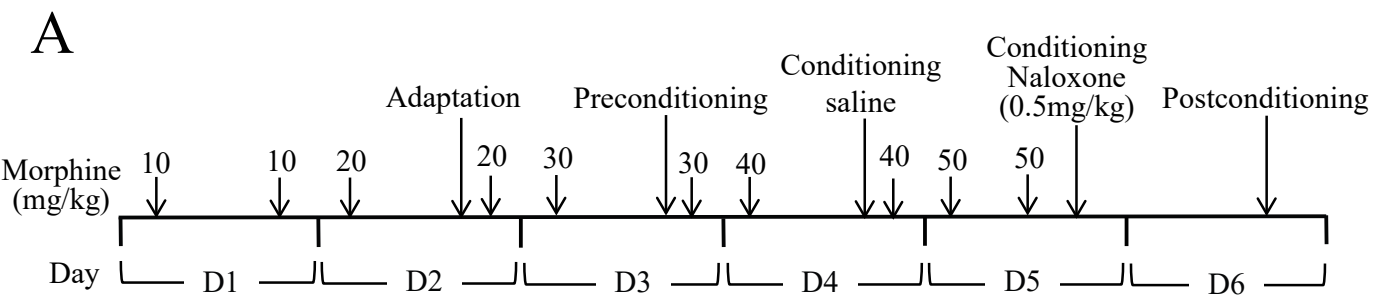

$\mathrm{B}$
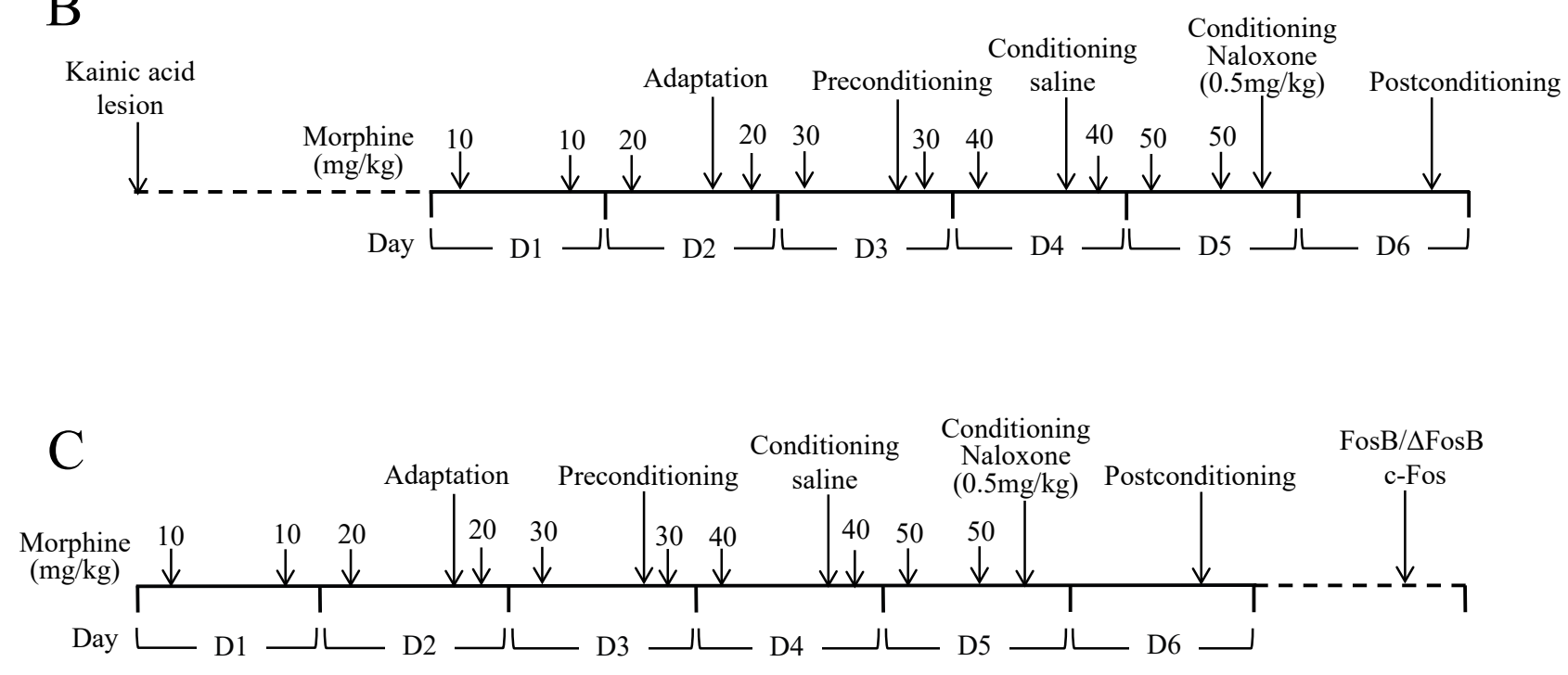

Fig. 1. Schematic timeline of behavioral procedure. A. CPA experimental procedure indicating time of morphine injection, adaptation, preconditioning, conditioning, and postconditioning sessions. B. Schematic timeline of insular cortex lesion and CPA experimental procedure. C. Schematic timeline of CPA experimental procedure and immunohistochemistry for FosB/ $\Delta$ FosB and c-Fos expressions in the insular cortex 


\section{Materials and Methods}

\section{Animals}

Male Swiss-Kunming mice, initially weighing between 25 and $30 \mathrm{~g}$, were obtained from the Experimental Animal Center of Shenyang Pharmaceutical University. Mice were housed four per cage under a controlled $12 \mathrm{~h}$ light-dark cycle with ad libitum water and food. Animal use was in accordance with the Guide for the Care and Use of Laboratory Animals (1985), NIH, Bethesda. All experimental procedures were approved by our University Committee on Animal Care and Use. Every effort was taken to minimize the number of animals used and their suffering.

\section{Condition place aversion model}

The place conditioning apparatus was made of opaque Plexiglas, and consisted of two rectangular-based chambers $(20 \times 15 \times 15 \mathrm{~cm}$ each $)$ separated by a guillotine door. One compartment had walls colored with alternating black and white horizontal stripes and a bar grid floor, whereas the other compartment had walls colored with black dots on a white background and a wire mesh floor (Han et al. 2014).

Eighty male mice were randomly divided into four groups: chronic morphine dependence with naloxone-precipitated withdrawal group ( $\mathrm{MN}$ group), chronic saline injection with naloxone treatment group (SN group), chronic morphine injection with saline treatment group (MS group) and chronic saline injection with saline treatment group (SS group). According to the schedule described in Figure 1A, morphine hydrochloride (Shenyang No.1 Pharmaceutical Co., Ltd, Shenyang, China) was injected intraperitoneally twice daily, at $8 \mathrm{AM}$ and $8 \mathrm{PM}$ (except last injection) in increased progressive doses over a period of 5 days: Day 1 (10 mg/kg, $10 \mathrm{mg} / \mathrm{kg})$, Day $2(20 \mathrm{mg} / \mathrm{kg}, 20 \mathrm{mg} / \mathrm{kg})$, Day 3 (30 mg/kg, $30 \mathrm{mg} / \mathrm{kg})$, Day 4 (40 mg/kg, $40 \mathrm{mg} / \mathrm{kg}$ ), Day 5 (50 mg/kg, $50 \mathrm{mg} / \mathrm{kg}$ at $12 \mathrm{PM})$.

On Day 1, the mice were injected with morphine or saline without being exposed to the place conditioning apparatus. On Days 2 (adaptation session) and 3 (preconditioning session), each mouse was allowed to freely explore the two compartments of the apparatus for $900 \mathrm{~s}$ at $2 \mathrm{PM}$ and the time spent in each compartment was recorded. Mice showing strong unconditioned preference (more than $720 \mathrm{~s}$ in one compartment during the preconditioning session or a difference of more than $200 \mathrm{~s}$ in one compartment between the adaptation session and the preconditioning session) were eliminated. An unbiased conditioning design was used wherein one compartment was chosen to be paired with naloxone and the other with saline, taking into account that half of the mice in each group received the treatment in one compartment and the rest in the other compartment. On Day 4 (conditioning session), all mice were confined to one compartment for $60 \mathrm{~min}$ immediately after the injection of saline at 2 PM. On Day 5 (conditioning session), the mice in $\mathrm{MN}$ and $\mathrm{SN}$ groups received naloxone hydrochloride dihydrate (Sigma, USA) $0.5 \mathrm{mg} / \mathrm{kg}$ injection, while the mice in SS and MS groups were injected with saline intraperitoneally with a volume of $0.1 \mathrm{ml} / 10 \mathrm{~g}$ at $2 \mathrm{PM}$, then immediately confined in the compartment for $60 \mathrm{~min}$, which was opposite to that used on Day 4. On Day 6 (post-conditioning session), all mice were allowed to freely explore both compartments for $900 \mathrm{~s}$, and the time spent in each compartment was recorded (Fig. 1A). The time spent in the naloxone-paired compartment during the pre- and post-conditioning sessions were recorded on video camera and place aversion behavior was analyzed using a tracking program (Computer Technology Center of Shenyang Pharmaceutical University, Shenyang, China). In total, sixty four mice (SS group: $n=17 ; \mathrm{SN}$ group: $\mathrm{n}=16$; MS group: $n=15$; $M N$ group: $n=16$ ) were used for statistical analysis.

\section{Kainic acid lesion and histological procedure}

Forty male mice were anesthetized with chloral hydrate $(350 \mathrm{mg} / \mathrm{kg}$, i.p.), and placed in a stereotaxic apparatus. Kainic acid (KA) (Sigma, USA) was dissolved in artificial cerebrospinal fluid (aCSF) $[147 \mathrm{mM} \mathrm{NaCl}$, $2.2 \mathrm{mM} \mathrm{CaCl}_{2}$ and $\left.4 \mathrm{mM} \mathrm{KCl}\right] 1 \mu \mathrm{g} / \mu \mathrm{KA}$ or aCSF was microinjected into the insular cortex bilaterally using a syringe connected with a microinfusion pump (KDS310, KD Scientific, Holliston, USA) at the following coordinates: $\mathrm{AP}+1.78 \mathrm{~mm} ; \mathrm{ML} \pm 3.10 \mathrm{~mm}$; DV $-3.10 \mathrm{~mm}$, according to the mouse brain atlas of Paxinos and Franklin (2001). KA or aCSF was microinjected in a volume of $0.3 \mu \mathrm{l}$ per side over a period of 3 min with the needle subsequently left in place for at least $5 \mathrm{~min}$ before retraction. All mice were allowed to recover for about 1 week before the CPA experiment was conducted (Fig. 1B).

After the CPA post-conditioning session, the mice were sacrificed and the brains were rapidly removed. Nissl staining was performed as described previously (Sun et al. 2011) to verify the lesion area. The 
data were discarded if the lesion position was incorrect. In total, twenty two mice (sham group: $n=10$; lesion group: $n=12$ ) were used for statistical analysis.

\section{Immunohistochemistry for FosB/ $\triangle F o s B$ and c-Fos in the} insular cortex

As shown in Figure 1C, $24 \mathrm{~h}$ after the CPA postconditioning session, four mice in each group were transcardially perfused. The brains were removed, postfixed for $3 \mathrm{~h}$ using $4 \%$ paraformaldehyde, then transferred to a $30 \%$ sucrose solution. Each brain was coronally sectioned at a thickness of $20 \mu \mathrm{m}$. After incubation for $30 \mathrm{~min}$ in $0.3 \% \mathrm{H}_{2} \mathrm{O}_{2}$-methanol and hyperbaric heating antigen retrieval, all sections were blocked in normal goat serum containing $0.3 \%$ Triton $\mathrm{X}-100$ for $30 \mathrm{~min}$ at $37^{\circ} \mathrm{C}$. Sections were incubated overnight in primary antiFosB/AFosB (SC-48, 1:400, Santa Cruz Biotechnology, Dallas, USA) or anti-c-Fos (SC-52, 1:400, Santa Cruz Biotechnology, USA) at $4{ }^{\circ} \mathrm{C}$. Thereafter, sections were incubated with biotinylated goat anti-rabbit IgG (Wuhan Boster Biological Technology, Wuhan, China) for $30 \mathrm{~min}$ at $37^{\circ} \mathrm{C}$. c-Fos and FosB/ $\triangle$ FosB immunoreactivity were visualized by the streptavidin-biotin technique using $\mathrm{DAB}$ as the chromogen.

The numbers of FosB/ $\Delta$ FosB and c-Fos positive cells were counted from four adjacent sections of the insular cortex of each mouse using the Olympus IX71 microscope interfaced with a CCD camera and Image-Pro Plus 6.0 image processing \& analysis software (Media Cybernetics, Silver Spring, USA). Three visual fields on each side of the insular cortex section were selected and the magnification used was $400 \times$. To avoid observer bias, all sections were quantified by a blinded investigator.

\section{Statistical analysis}

For the CPA experiment, the difference of the time during each session among four groups was analyzed by one-way ANOVA followed by LSD test. For the KA lesion experiment, the difference of the time between the sham and KA lesion groups during each session was analyzed by independent-samples $t$ test. In the above experiments, the difference between pre- and post-conditioning sessions in each group was analyzed by a two-tailed paired t-test. For immunohistochemistry, the difference of the numbers of FosB/ $\Delta$ FosB or c-Fos among four groups was analyzed by one-way ANOVA followed by LSD test. All data are expressed as mean \pm SEM. Results were considered significant at $\mathrm{P}<0.05$. All statistical procedures were performed using SPSS 16.0
(SPSS Inc., Chicago, IL, USA).

\section{Results}

\section{Naloxone-precipitated CPA in morphine dependent mice}

One-way ANOVA analysis showed that during the preconditioning session, the time spent in the naloxonepaired compartment was not significantly different when comparing the four groups $(\mathrm{F}(3,60)=0.125, \mathrm{P}>0.05)$. After the conditioning session, the time spent in the naloxonepaired compartment among four groups was significantly different $(\mathrm{F}(3,60)=4.156, \mathrm{P}<0.01)$, the mice in the $\mathrm{MN}$ group spent less time than mice in the other three groups $(\mathrm{P}<0.05, \mathrm{P}<0.01)$. Two-tailed paired t-test analysis showed that mice in the MN group spent significantly less time in the naloxone-paired compartment during the postconditioning vs. the preconditioning session $(\mathrm{t}(15)=3.458$, $\mathrm{P}<0.01$, Fig. 2).

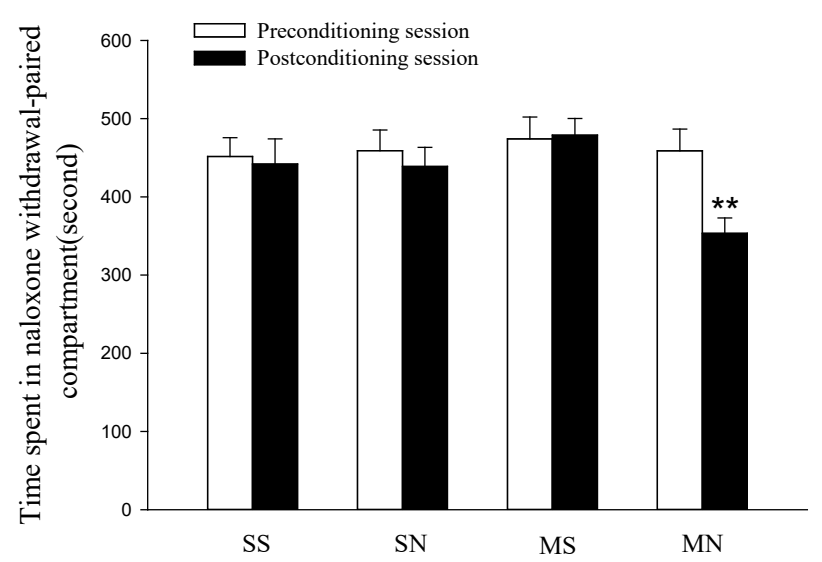

Fig. 2. Naloxone-induced CPA in morphine-dependent mice. Data are expressed as mean \pm S.E.M. SS: saline+saline group, $n=17$; $\mathrm{SN}$ : saline+naloxone group, $\mathrm{n}=16$; $\mathrm{MS}$ : morphine+saline group, $\mathrm{n}=15 ; \mathrm{MN}$ : morphine+naloxone group, $\mathrm{n}=16$. ** $\mathrm{P}<0.01$, compared to the preconditioning session of the $\mathrm{MN}$ group

Influence of the insular cortex lesion on naloxoneprecipitated CPA in morphine-dependent mice

The influence of the insular cortex lesion induced by kainic acid on the CPA is shown in Figure 3A. Mice in the sham group spent less time in the naloxone-paired compartment during the postconditioning vs. the pre-conditioning sessions $(\mathrm{t}(9)=4.821, \mathrm{P}<0.01$, two-tailed paired t-test, Fig. 3A), indicating that mice in the sham group generated a significant conditioned aversion. Although the time spent in the naloxone-paired compartment during the preconditioning session was not different between the 
sham and KA lesion groups $(\mathrm{t}=-0.477, \mathrm{P}>0.05$, independent-samples $\mathrm{t}$ test), after the conditioning session, however, the time spent in the naloxone-paired compartment was significantly increased in the KA lesion vs. sham group $(\mathrm{t}=-4.346, \mathrm{P}<0.01$, independent-samples $\mathrm{t}$ test, Fig. 3A). Two-tailed paired t-test analysis also showed that the time spent in the naloxone-paired compartment in the KA lesion group was not significantly different between the pre- and post- conditioning sessions $(\mathrm{t}(11)=-2.063, \mathrm{P}>0.05)$. Bilateral insular cortex lesions completely inhibited the CPA.

Histological results showed that the mice that were given KA infusion into the insular cortex bilaterally, exhibited moderate to extensive damage around the KA injection site. Schematic representation of the KA lesion showed that there was no obvious extra-structural damage (Fig. 3B). The loss of neuron in the insular cortex is shown in Figure 3C.
A

尊

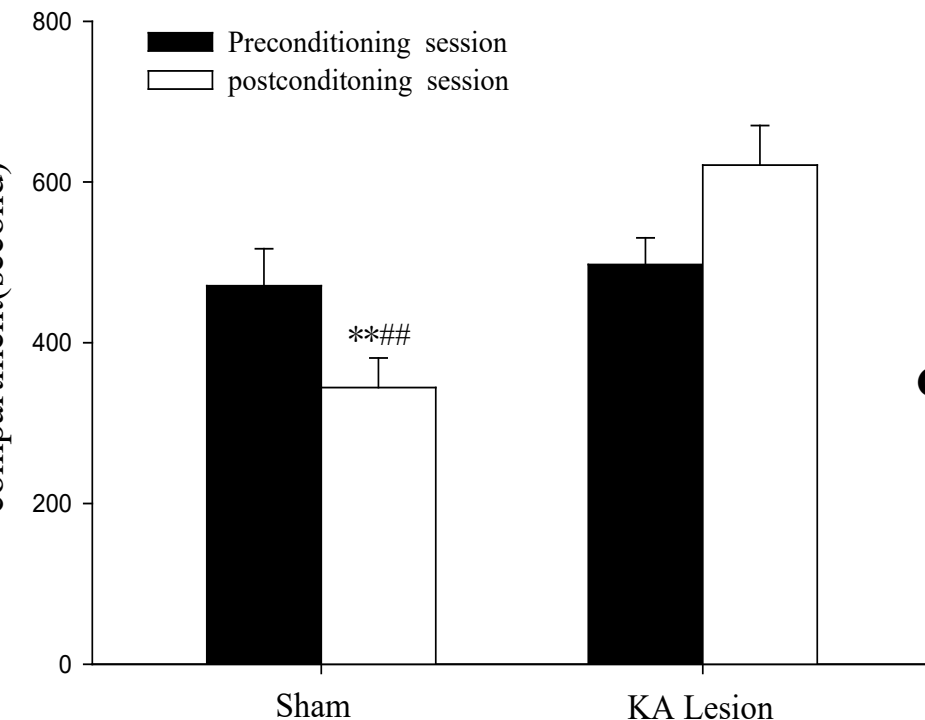

B

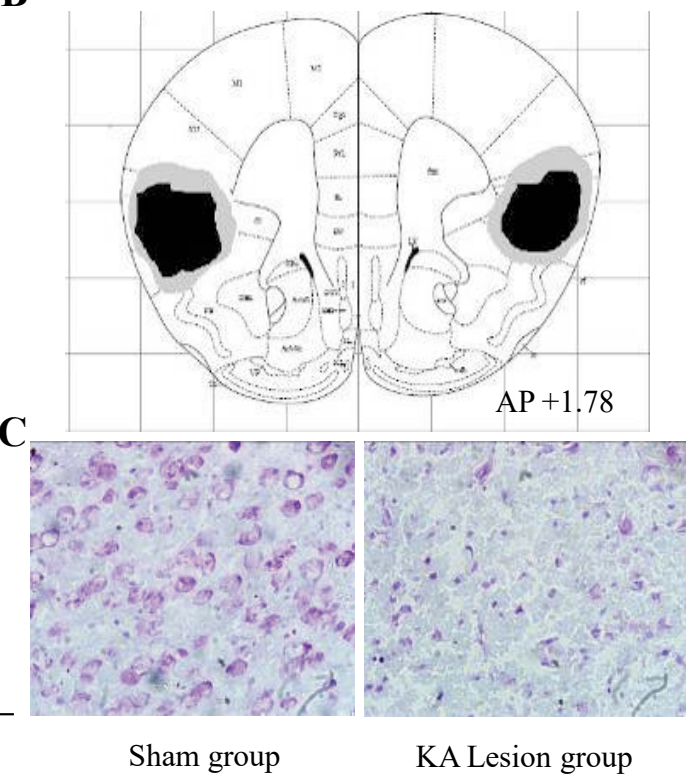

Fig. 3. Influence of insular cortex lesion on CPA in morphine-dependent mice. A. Changes in the time mice stayed in the naloxonepaired compartment. (Sham group: $n=10$; KA lesion group: $n=12$ ). B. Schematic representation of bilateral insular cortex lesions. Shaded areas represent the smallest (black) and largest (gray) extent of neuronal damage. The number indicates the distance (mm) anterior to bregma. C. Nissl staining of the insular cortex after KA lesion in the mice $(\times 400)$. $* * P<0.01$ compared to the preconditioning session of the sham group. \#\# $\mathrm{P}<0.01$ compared to the postconditioning session of the KA lesion group

Expressions of FosB/ $\triangle F O S B$ in the bilateral insular cortex after the expression of CPA model

As shown in Figure 4A, the expression of FosB/ $\Delta$ FosB in the insular cortex was significantly different $24 \mathrm{~h}$ after the CPA was performed $(\mathrm{F}(3,12)=15.082, \quad \mathrm{P}<0.001) . \quad$ The expressions of $\mathrm{FosB} / \Delta \mathrm{FosB}$ in the $\mathrm{MN}$ group were significantly increased compared with the other three groups $(\mathrm{P}<0.001$, Fig. 4A). Figure 4B shows representative photomicrographs of $\mathrm{FosB} / \Delta \mathrm{FosB}$-positive nuclei in the insular cortex.

Expressions of c-Fos in the bilateral insular cortex after the expression of CPA model

c-Fos expression in the insular cortex was not significantly different $24 \mathrm{~h}$ following CPA $(F(3,12)=0.544, P>0.05)$. c-Fos expressions in the insular cortex in the $\mathrm{MN}$ group were not significantly changed compared to the other three groups $(\mathrm{P}>0.05)$ (Fig. 5A). Figure 5B shows representative photomicrographs of c-Fos-positive nuclei in the insular cortex.

\section{Discussion}

CPA is a form of Pavlovian conditioning used to measure the motivational aversion associated with opioid withdrawal. It is thought to be a more sensitive index of withdrawal than the somatic signs of opiate withdrawal (Li et al. 2007). In this study, we first established a mouse CPA model with an unbiased conditioning paradigm revised according to the method described previously (Hikida et al. 2003, Olson et al. 2006, Sato et al. 2005). Our result proved that the mice in the $\mathrm{MN}$ group showed significant conditioned aversion, while the 
A

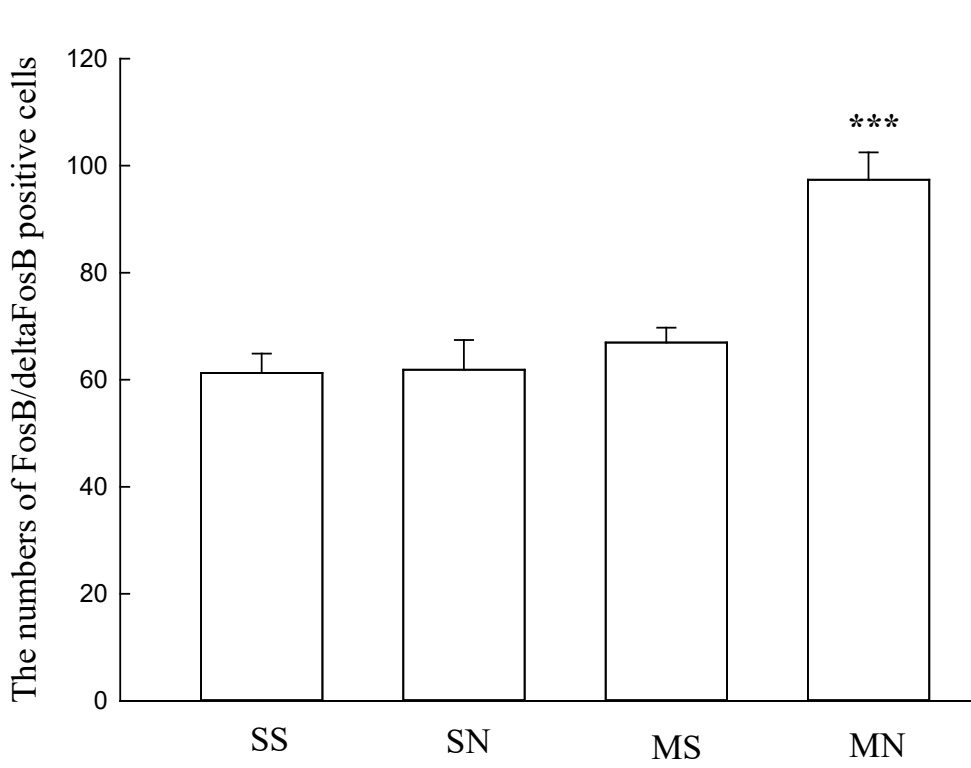

B

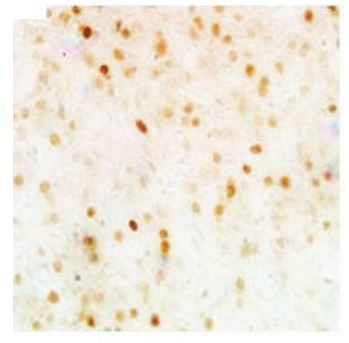

SS group

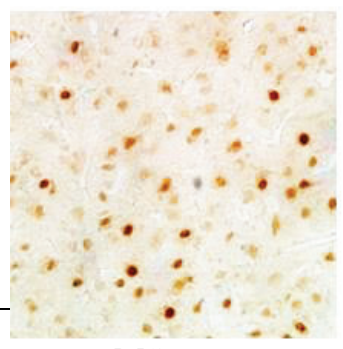

MS group

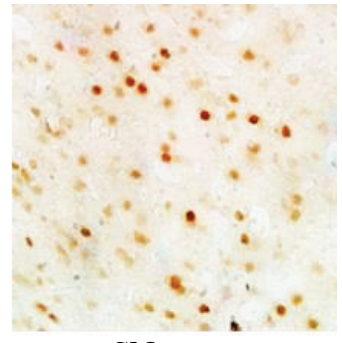

$\mathrm{SN}$ group

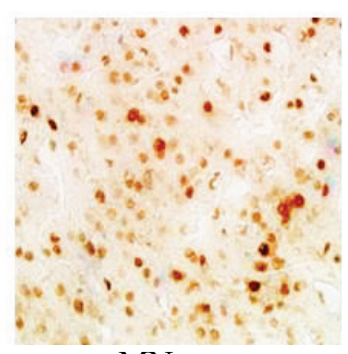

MN group

Fig. 4. Expression of FosB $/ \triangle \mathrm{FosB}$ in the insular cortex after the expression of $C P A$ model. $A$. Number of FosB/ $\triangle$ FosB positive cells in the insular cortex. B. Representative photomicrographs of FosB/ $\triangle F$ osB in the insular cortex $(\times 400)$. $* * * P<0.001$ compared to the SS group. SS: saline+saline group, $n=4$; $S N$ : saline+naloxone group, $n=4$; MS: morphine+saline group, $n=4$; $M N$ : morphine+naloxone group, $\mathrm{n}=4$

A

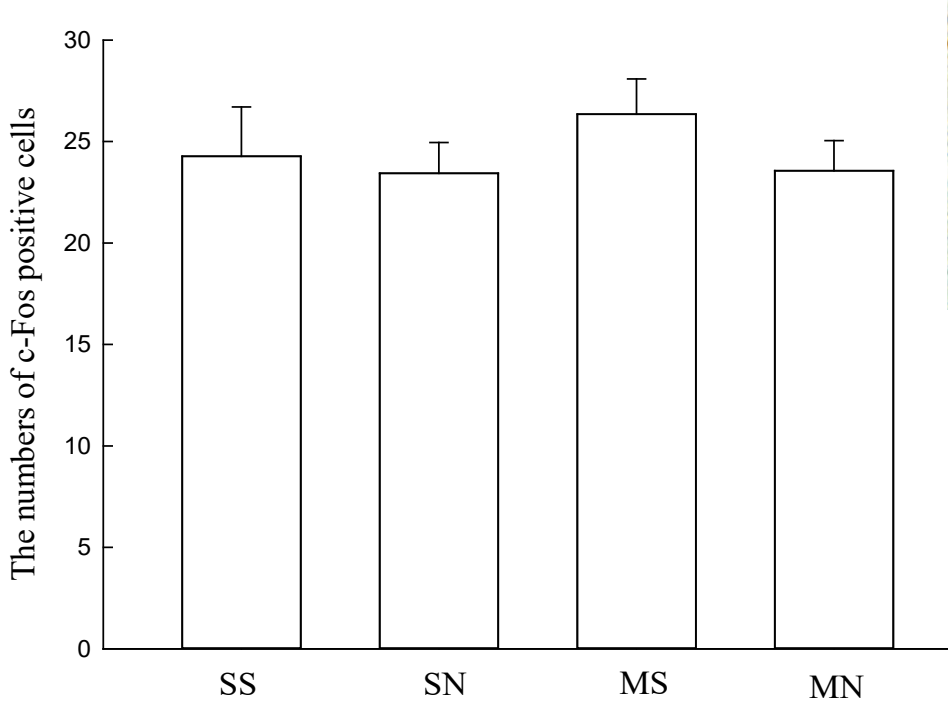

B

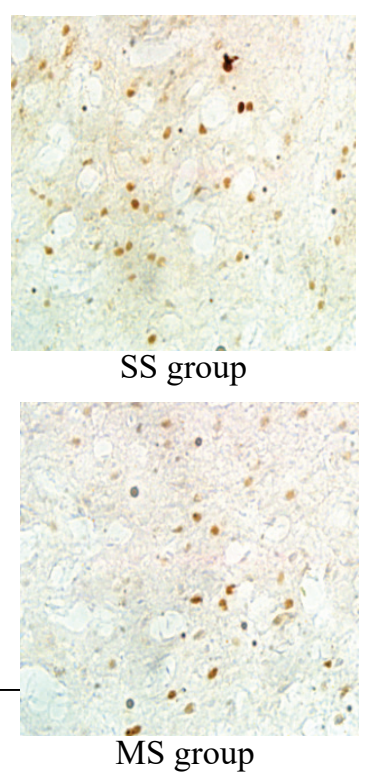

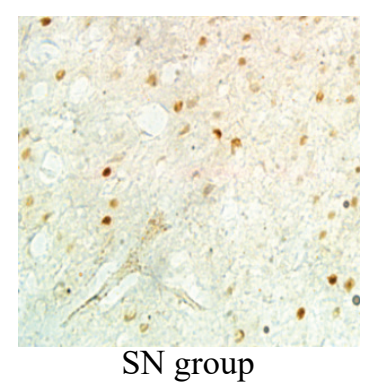

SN group

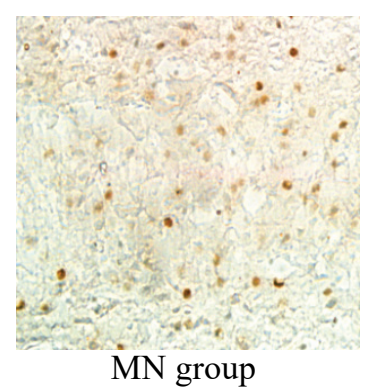

Fig. 5. Expression of c-Fos in the insular cortex after the expression of CPA model. A. Number of c-Fos positive cells in the insular cortex. B. Representative photomicrographs of c-Fos in the insular cortex $(\times 400)$. SS: saline+saline group, $n=4$; $S N$ : saline+naloxone group, $n=4$; MS: morphine+saline group, $n=4$; $M N$ : morphine+naloxone group, $n=4$

mice in other control groups did not. The data suggest that the formation of conditioned aversion was dependent on the repeated morphine administration combined with naloxone-precipitated withdrawal.

By using this established CPA model, we investigated the integrity of the insular cortex on motivational aversion associated with naloxone- precipitated withdrawal in morphine dependent mice. KA is widely used to damage the specific brain region as a chemical neurotoxin, which can destroy cell bodies without disrupting fibers of passage and axon terminals (Pazo et al. 1993). Our results show for the first time that the expression of CPA was completely inhibited after KA was bilaterally injected into the insular cortices in mice. 
A previous study reported that reversible inactivation of the insular cortex by a mixture of $\mathrm{GABA}_{\mathrm{B}}$ agonist and $\mathrm{GABA}_{\mathrm{A}}$ receptor agonist impaired the acquisition of CPA in rats (Li et al. 2013). Although the impairment methods of neuronal activity in the insular cortex and the species of animals are different, the impairment of CPA in mice after the insular cortex lesion reported here is consistent with the previous report that reversible inactivation of the insular cortex can disrupt the acquisition of CPA in rats. Our results together with a previous study, suggest that the integrity of the insular cortex is necessary for exhibiting the motivational aversion associated with opiate withdrawal.

In the present study, FosB/ $\Delta$ FosB and c-Fos levels in the insular cortex were investigated $24 \mathrm{~h}$ after CPA was performed. FosB and $\triangle$ FosB are members of the Fos family, and are implicated in neural plasticity in addiction (Kaplan et al. 2011). The highly stable 35-37 $\mathrm{kDa}$ isoforms of $\Delta \mathrm{FosB}$ - truncated splice variant of full-length FosB that lacks a portion of the C-terminal domain presented in other Fos proteins (Marttila et al. 2006) - are thought to be the initial step of the process that leads to alteration of synaptic organization and mediation of long-lasting plasticity (Conversi et al. 2006). Unlike full-length FosB that is expressed rapidly and transiently, $\Delta$ FosB gradually accumulates over a relatively long period after repeated stimuli because of its very long half-life and extraordinary stability (McClung et al. 2004, Nestler et al. 2001). Our result found that the expression of FosB/ $\Delta$ FosB in the insular cortex was significantly increased $24 \mathrm{~h}$ after the CPA was performed. Since FosB-like immunoreactivity observed $24 \mathrm{~h}$ after drug withdrawal has been proved to mainly represent the stable $35-37 \mathrm{kDa}$ isoforms of $\Delta$ FosB (Wang et al. 2005), our results indicate that besides the classic addiction-related brain areas (Nunez et al. 2010, Wang et al. 2005), long-lasting neural plasticity is also induced in the insular cortex, the largely overlooked structure in the field of addiction. Also, overexpression of $\triangle \mathrm{FosB}$ was found to increase rewarding responses (Muschamp et al. 2012), whereas mice lacking fosB were less sensitive to rewarding properties (Solecki et al. 2008). Therefore, we suggest that the increase in FosB/ $\Delta$ FosB expression in the insular cortex may be related with $\mathrm{CPA}$ behavioral outcomes. Although the present results do not prove a causal relationship between the motivational aversion associated with morphine withdrawal and the increase in FosB/ $\Delta$ FosB expression, it is possible that the two events may be linked. As another prototypical transcription factor of the Fos family, c-Fos is usually used as a marker for postsynaptic activation (Morgan and Curran 1991). Most studies reported that the expression of c-Fos was rapid and transient after chronic addiction drug administration and withdrawal (Larson et al. 2010, Veinante et al. 2003). However, Marttila et al. (2006) reported that the number of c-Fos positive nuclei in the caudate-putamen was higher in nicotine-treated mice than that in the control mice on the 50th day of the 7-week nicotine treatment. Another study also showed that the expression of c-Fos in the ventral tegmental area after $24 \mathrm{~h}$ of naltrexone-precipitated opiate withdrawal was lower than that after $6 \mathrm{~h}$ of withdrawal, but still higher compared with the control group (Nye and Nestler 1996). Under our experimental protocol and withdrawal severity, the expression of c-Fos in the insular cortex was not changed $24 \mathrm{~h}$ after CPA was performed. These differences might result from the experimental protocol used, the methods of inducing addiction and its severity, and the species of animals utilized.

Converging evidence have reported that the expression of FosB/ $\triangle F$ FosB is dependent on activation of the $\mathrm{D}_{1}$ type of dopamine receptors (Muller and Unterwald 2005). Because the insular cortex contains a high density of $\mathrm{D}_{1}$ dopamine receptors and receives strong dopaminergic innervation (Naqvi and Bechara 2009), the increase of $\mathrm{FosB} / \Delta \mathrm{FosB}$ expression in the insular cortex may be modulated by the $D_{1}$ receptor and related to downstream transcriptional pathway. Further studies are needed to understand the detailed mechanisms involved.

In conclusion, our results suggest that the integrity of the insular cortex is important in regulating motivational aversion associated with opiate withdrawal in mice. This type of aversion induces neuroadaptation, observed as the increase of FosB $/ \Delta$ FosB expression in the insular cortex.

\section{Conflict of Interest}

There is no conflict of interest.

\section{Acknowledgements}

We would like to thank Brian Wang for taking the time to proofread the manuscript. This work was supported by the grants from the Natural Science Foundation of Liaoning Province of China (20102212) and the Program for Liaoning Excellent Talents in University, China (LJQ2012089).

Present address of Xiaolong Jing: Tianjin Institute of Pharmaceutical Research, Tianjin 300193, China 


\section{References}

ABDOLAHI A, ACOSTA G, BRESLIN FJ, HEMBY SE, LYNCH WJ: Incubation of nicotine seeking is associated with enhanced protein kinase A-regulated signaling of dopamine- and cAMP-regulated phosphoprotein of $32 \mathrm{kDa}$ in the insular cortex. Eur J Neurosci 31: 733-741, 2010.

CONTRERAS M, CERIC F, TORREALBA F: Inactivation of the interoceptive insula disrupts drug craving and malaise induced by lithium. Science 318: 655-658, 2007.

CONVERSI D, BONITO-OLIVA A, ORSINI C, CABIB S: Habituation to the test cage influences amphetamineinduced locomotion and Fos expression and increases FosB/DeltaFosB-like immunoreactivity in mice. Neuroscience 141: 597-605, 2006.

DI PIETRO NC, MASHHOON Y, HEANEY C, YAGER LM, KANTAK KM: Role of dopamine D1 receptors in the prefrontal dorsal agranular insular cortex in mediating cocaine self-administration in rats. Psychopharmacology (Berl) 200: 81-91, 2008.

EDWARDS S, KOOB GF: Neurobiology of dysregulated motivational systems in drug addiction. Future Neurol 5: 393-401, 2010.

FORGET B, PUSHPARAJ A, LE FOLL B: Granular insular cortex inactivation as a novel therapeutic strategy for nicotine addiction. Biol Psychiatry 68: 265-271, 2010.

HAN WY, DU P, FU SY, WANG F, SONG M, WU CF, YANG JY: Oxytocin via its receptor affects restraint stressinduced methamphetamine CPP reinstatement in mice: Involvement of the medial prefrontal cortex and dorsal hippocampus glutamatergic system. Pharmacol Biochem Behav 119: 80-87, 2014.

HIKIDA T, KITABATAKE Y, PASTAN I, NAKANISHI S: Acetylcholine enhancement in the nucleus accumbens prevents addictive behaviors of cocaine and morphine. Proc Natl Acad Sci U S A 100: 6169-6173, 2003.

KAPLAN GB, LEITE-MORRIS KA, FAN W, YOUNG AJ, GUY MD: Opiate sensitization induces FosB/DeltaFosB expression in prefrontal cortical, striatal and amygdala brain regions. PLoS One 6: e23574, 2011.

KOOB GF: Dynamics of neuronal circuits in addiction: reward, antireward, and emotional memory. Pharmacopsychiatry 42 (Suppl 1): S32-S41, 2009.

KOOB GF, VOLKOW ND: Neurocircuitry of addiction. Neuropsychopharmacology 35: 217-238, 2010.

LARSON EB, AKKENTLI F, EDWARDS S, GRAHAM DL, SIMMONS DL, ALIBHAI IN, NESTLER EJ, SELF DW: Striatal regulation of DeltaFosB, FosB, and cFos during cocaine self-administration and withdrawal. $J$ Neurochem 115: 112-122, 2010.

LI CL, ZHU N, MENG XL, LI YH, SUI N: Effects of inactivating the agranular or granular insular cortex on the acquisition of the morphine-induced conditioned place preference and naloxone-precipitated conditioned place aversion in rats. $J$ Psychopharmacol 27: 837-844, 2013.

LI Y, LIU X, CHEN H, DENG H, XIANG X, HAO W: Development, extinction and reinstatement of morphine withdrawal-induced conditioned place aversion in rats. Addict Biol 12: 470-477, 2007.

MARTTILA K, RAATTAMAA H, AHTEE L: Effects of chronic nicotine administration and its withdrawal on striatal FosB/DeltaFosB and c-Fos expression in rats and mice. Neuropharmacology 51: 44-51, 2006.

MCCLUNG CA, ULERY PG, PERROTTI LI, ZACHARIOU V, BERTON O, NESTLER EJ: DeltaFosB: a molecular switch for long-term adaptation in the brain. Brain Res Mol Brain Res 132: 146-154, 2004.

MORGAN JI, CURRAN T: Stimulus-transcription coupling in the nervous system: involvement of the inducible protooncogenes fos and jun. Annu Rev Neurosci 14: 421-451, 1991.

MULLER DL, UNTERWALD EM: D1 dopamine receptors modulate deltaFosB induction in rat striatum after intermittent morphine administration. J Pharmacol Exp Ther 314: 148-154, 2005.

MUSCHAMP JW, NEMETH CL, ROBISON AJ, NESTLER EJ, CARLEZON WA Jr: $\triangle$ FosB enhances the rewarding effects of cocaine while reducing the pro-depressive effects of the kappa-opioid receptor agonist U50488. Biol Psychiatry 71: 44-50, 2012.

NAQVI NH, BECHARA A: The hidden island of addiction: the insula. Trends Neurosci 32: 56-67, 2009.

NAQVI NH, RUDRAUF D, DAMASIO H, BECHARA A: Damage to the insula disrupts addiction to cigarette smoking. Science 315: 531-534, 2007. 
NESTLER EJ, BARROT M, SELF DW: DeltaFosB: a sustained molecular switch for addiction. Proc Natl Acad Sci US A 98: 11042-11046, 2001.

NUNEZ C, MARTIN F, FOLDES A, LUISA LAORDEN M, KOVACS KJ, VICTORIA MILANES M: Induction of FosB/DeltaFosB in the brain stress system-related structures during morphine dependence and withdrawal. J Neurochem 114: 475-487, 2010.

NYE HE, NESTLER EJ: Induction of chronic Fos-related antigens in rat brain by chronic morphine administration. Mol Pharmacol 49: 636-645, 1996.

OLSON VG, GRINER NB, HEUSNER CL, PALMITER RD: Lack of neuropeptide Y attenuates the somatic signs of opiate withdrawal. Synapse 60: 553-556, 2006.

PAXINOS G, FRANKLIN KBJ: The Mouse Brain in Stereotaxic Coordinates. Academic Press, San Diego, 2001.

PAZO JH, MURER GM, SEGAL E: D1 and D2 receptors and circling behavior in rats with unilateral lesion of the entopeduncular nucleus. Brain Res Bull 30: 635-639, 1993.

SATO M, WADA K, FUNADA M: Barium potentiates the conditioned aversion to, but not the somatic signs of, morphine withdrawal in mice. Eur J Pharmacol 519: 215-222, 2005.

SLOUZKEY I, ROSENBLUM K., MAROUN M: Memory of conditioned taste aversion is erased by inhibition of PI3K in the insular cortex. Neuropsychopharmacology 38: 1143-1153, 2013.

SOLECKI W, KROWKA T, KUBIK J, KACZMAREK L, PRZEWLOCKI R: Role of fosB in behaviours related to morphine reward and spatial memory. Behav Brain Res 190: 212-217, 2008.

STARK R, ZIMMERMANN M, KAGERER S, SCHIENLE A, WALTER B, WEYGANDT M, VAITL D: Hemodynamic brain correlates of disgust and fear ratings. Neuroimage 37: 663-673, 2007.

SUN JY, YANG JY, WANG F, WANG JY, SONG W, SU GY, DONG YX, WU CF: Lesions of nucleus accumbens affect morphine-induced release of ascorbic acid and GABA but not of glutamate in rats. Addict Biol 16: 540-550, 2011.

VEINANTE P, STOECKEL ME, LASBENNES F, FREUND-MERCIER MJ: c-Fos and peptide immunoreactivities in the central extended amygdala of morphine-dependent rats after naloxone-precipitated withdrawal. Eur J Neurosci 18: 1295-1305, 2003.

WANG HL, XIANG XH, GUO Y, WU WR, CAO DY, WANG HS, ZHAO Y: Ionotropic glutamatergic neurotransmission in the ventral tegmental area modulates DeltaFosB expression in the nucleus accumbens and abstinence syndrome in morphine withdrawal rats. Eur J Pharmacol 527: 94-104, 2005. 